\title{
Selected oxidative stress markers in gynecological laparoscopy
}

\author{
Jacek Koźlik ${ }^{1,2}$, Joanna Przybyłowska ${ }^{2}$, Kinga Mikrut ${ }^{1}$, Wioletta A. Żukiewicz-Sobczak ${ }^{3}$, Jacek Zwoliński ${ }^{3}$, \\ Jacek Piątek ${ }^{1,3}$, Paweł Sobczak ${ }^{4}$ \\ 1Department of Physiology, Poznan University of Medical Sciences, Poznan, Poland \\ 2Department of Gynecology and Obstetrics, F. Raszeja Hospital, Poznan, Poland \\ ${ }^{3}$ Department of Allergology and Environmental Hazards, Institute of Rural Health, Lublin, Poland \\ ${ }^{4}$ Department of Food Engineering and Machines, University of Life Sciences, Lublin, Poland
}

Videosurgery Miniinv 2015; 10 (1): 92-100 DOI: $10.5114 /$ wiitm.2014.47449

\begin{abstract}
Introduction: The surgical stress response after laparoscopy is smaller when compared with open surgery, and it is expected that after minimally invasive surgery the possible development of oxidative stress will be less severe.

Aim: To evaluate markers of pro-oxidant activity - levels of lipid peroxides and malondialdehyde - and activity of the antioxidant enzymes superoxide dismutase and glutathione peroxidase in the perioperative period in patients undergoing gynecological laparoscopy and to determine whether the duration of laparoscopy can affect these changes. Material and methods: The study included 64 patients, divided into two groups: group 1 with duration of laparoscopy up to $20 \mathrm{~min}$, and group 2 with duration of the operation over $40 \mathrm{~min}$. Blood samples were collected before anesthesia, 5 min after release of pneumoperitoneum, and $10 \mathrm{~h}$ after surgery.

Results: A statistically significant increase in the levels of lipid peroxides and malondialdehyde in samples collected after surgery was found in comparison with values obtained before surgery. Also statistically significant differences existed between groups of patients with different duration of surgery. Superoxide dismutase and glutathione peroxidase activity values were significantly decreased. They were also significantly different between the two groups with different duration of surgery.

Conclusions: In our study, levels of the markers of pro-oxidant activity increased and levels of the markers of antioxidant enzymes decreased, suggesting development of oxidative stress. The duration of laparoscopic procedures affects the severity of the presented changes.
\end{abstract}

Key words: gynecological laparoscopy, duration of laparoscopy, oxidative stress.

\section{Introduction}

Each operation is an injury that causes a hormonal, metabolic, immune and hemodynamic imbalance [1]. They create an image of the surgical stress response [2]. Injury, septic shock and surgical stress lead to increased production of free radicals [3]. And surgical stress can be associated with increased levels of lipid peroxides. It was confirmed by Szymczyk et al. [4] with women after abdominal hysterectomy.
This may be associated with activation of polymorphonuclear neutrophils generating superoxide anion. Abe et al. [5] observed release of active forms of oxygen in the early postoperative period by neutrophils. Deitch et al. [6] postulated that the source of reactive oxygen species (ROS) in operative stress may be the activation of xanthine oxidase, persisting in his studies until the first day after surgery. Excessive production of free radicals and decreased

\section{Address for correspondence}

Dr. Wioletta A. Żukiewicz-Sobczak, Department of Allergology and Environmental Hazards, Institute of Rural Health, 2 Jaczewskiego St, 20-090 Lublin, Poland, fax: +48 698143 743, e-mail: wiola.zukiewiczsobczak@gmail.com 
activity of antioxidant mechanisms lead to damage of macromolecules and disorders of cell metabolism, the state described as oxidative stress.

The factors responsible for the rise of oxidative stress during laparotomy are the manipulation of intestines, decreased perfusion in the visceral area and the formation of an ischemia-reperfusion syndrome, injury of the peritoneum, and inflammatory cell stimulation [7]. Less trauma to the peritoneum, and intestines or formation of pneumoperitoneum may cause differences in the generation of postoperative oxidative stress.

In recent years there have been reports of oxidative stress in the perioperative period in patients undergoing laparoscopy. Most of these concern surgical and urological operations and experimental studies carried out on animals.

In the available literature, there are very few reports on oxidative stress during gynecological laparoscopy. Usually cited is the work of Zhang et al. [8], as well as Aran et al. [9].

\section{Aim}

Assessment of pro-oxidative mechanism markers (malondialdehyde (MDA) and lipid peroxides) and activity of antioxidant systems (superoxide dismutase (SOD) and glutathione peroxidase) during gynecological laparoscopy. Determination of the relationship between the duration of the operation and the level of the studied parameters.

\section{Material and methods}

The study was conducted in a group of 83 patients who underwent surgery in the Department of Gynecology and Obstetrics of F. Raszeja Hospital in Poznan. It obtained ethical approval from the Bioethics Committee of the Medical University of Poznan (Resolution No. 262). The study involved women with operational risk ASA I/II. The study excluded patients burdened with additional diseases, and taking medication or hormonal contraceptives within 2 months prior to the surgery. Persons under 20 and over 30 years of age, and with body mass index (BMI) over $25 \mathrm{~kg} / \mathrm{m}^{2}$, were excluded.

In the chosen group indications for surgery included cases of primary infertility (19), secondary infertility (14), pelvic pain syndrome (10), a suspected pelvic endometriosis (19), and ovarian cysts (21). During the operation, in 4 cases it was necessary to proceed to laparotomy. After the operation, patients were divided into groups according to the length of laparoscopy (up to $20 \mathrm{~min}$, from 21 to $40 \mathrm{~min}$, more than $40 \mathrm{~min}$ ), and 11 patients with the duration of the operation between 21 and 40 min were excluded from further investigations. In 1 case fever occurred on the first day after the surgery. Also in 3 cases, not all laboratory tests were performed. Finally, the results of tested samples obtained from 64 patients divided into 2 groups were analyzed (Table I).

All patients were operated on by the same operating team. Patients were premedicated in the evening and $1 \mathrm{~h}$ before the surgery with midazolam $0.1 \mathrm{mg} / \mathrm{kg}$. The anesthesia was started with propofol $1.5-2.5 \mathrm{mg} / \mathrm{kg}$, vecuronium $0.08-0.1 \mathrm{mg} / \mathrm{kg}$, fentanyl $2.5-4.0 \mathrm{mg} / \mathrm{kg}$. General anesthesia was used in a semi-closed system, with monitoring of electrocardiogram, non-invasive blood pressure, saturated pressure of arterial oxygen, heart rate, end tidal carbon dioxide, capnography curve, the concentration of anesthetic gases, and neuromuscular transmission (NMT). Anesthesia was continued with 1 MAC of sevoflurane, fentanyl $2.5-4.0 \mathrm{mg} /$ $\mathrm{kg}$, and vecuronium $0.05 \mathrm{mg} / \mathrm{kg}$. For ventilation, a mixture of air with oxygen $\left(\mathrm{FiO}_{2}=0.4\right)$ was used. Laparoscopy was performed using laparoscopic sets of Aesculap and RZ-Medizintechnik. Aesculap insufflators established intraperitoneal pressure of $13 \mathrm{~mm} \mathrm{Hg}$. When replacing tools or aspirating, gas flows were increased so that pressure fluctuations did not exceed $\pm 1 \mathrm{~mm} \mathrm{Hg}$. Three or four trocars were pierced in conventional places. The electro-

Table I. Characteristics of patients

\begin{tabular}{|lcc|}
\hline Group & Group $1(<20 \mathrm{~min})$ & Group $2(>40 \mathrm{~min})$ \\
\hline Number of patients, $n$ & 33 & 31 \\
\hline Age of patients, median (range) [years] & $25(21-28)$ & $25(20-28)$ \\
\hline BMl, median (range) $\left[\mathrm{kg} / \mathrm{m}^{2}\right]$ & $19.7(18.3-21.2)$ & $20.2(18.7-22.0)$ \\
\hline Duration of operation, median (range) $[\mathrm{min}]$ & $19(15-20)$ & $43(41-50)$ \\
\hline
\end{tabular}


surgical set consisted of mono- and bipolar instruments, with an argon module and vessel sealing system. Tissues were removed from the abdominal cavity with extraction bags. Duration of laparoscopy was counted from the moment of puncture with a Veress needle until removing the last trocar and elimination of pneumoperitoneum.

During the laparoscopy lasting less than $20 \mathrm{~min}$ (group 1), chromoscopy was performed to assess the patency of the fallopian tubes. Cauterization of the ovaries was also done, single endometriosis foci were coagulated, and mild adhesions were freed.

During the laparoscopy lasting over $40 \mathrm{~min}$ (group 2), numerous adhesions were freed and endometriosis foci were coagulated. In case of fallopian hydrosalpinx, salpingostomy was performed. Paraovarian cysts were excised. Theca lutein cysts and ovary cystic teratomas were enucleated.

\section{Sampling}

Blood was collected into heparinized $6 \mathrm{ml}$ tubes three times: 1) immediately prior to anesthesia, 2) immediately after the operation ( 5 min after the release of pneumoperitoneum), 3) $10 \mathrm{~h}$ after the operation, while performing routine blood tests.

The collected samples were centrifuged at 3500 rpm at $4^{\circ} \mathrm{C}$. The resulting plasma was frozen, and $0.9 \% \mathrm{NaCl}$ was added to the cells in the ratio $1: 1$; these were then mixed and centrifuged three times at $3500 \mathrm{rpm}$ for $10 \mathrm{~min}$ at $4^{\circ} \mathrm{C}$. Washed red cells were divided into two samples, and distilled water in a 1 : 1 ratio was added. In plasma the levels of lipid peroxides and MDA were determined. In the hemolysate, activity of glutathione peroxidase and SOD was determined.

\section{Determination of malondialdehyde concentration in plasma}

To determine the concentration of MDA in plasma, the BIOXYTECH LPO-586 (Oxis International Inc., USA) test was used. The product of the test is a stable chromophore whose absorbance is measured spectrophotometrically at a wavelength of $586 \mathrm{~nm}$.

Calculating the absorbance of test samples was preceded by measuring the absorbance of standard samples with known and increasing concentrations of MDA. A standard curve was plotted according to the manufacturer. For final calculation of the concentration of MDA in the sample, the pattern recom- mended by the producer was used. The results were expressed in micromoles per liter.

\section{Determination of the concentration of lipid peroxides in plasma}

To determine the lipid peroxide level in the plasma, the BIOXYTECH LPO-560 (Oxis International Inc., USA) test was used. This test uses a colorimetric method based on the ability of peroxide to oxidize ferrous ions $\left(\mathrm{Fe}^{2+}\right)$ to ferric ions $\left(\mathrm{Fe}^{3+}\right)$, and, combined with the color indicator xylenol orange, form a complex whose absorbance is measured with a spectrophotometer at a wavelength of $560 \mathrm{~nm}$. Adding the substance reducing lipid peroxides to part of the sample allowed the creation of a blank. The concentration of lipid peroxides was calculated from the formula recommended by the manufacturer. The results were expressed in micromoles per liter.

\section{Determination of superoxide dismutase (EC.1.15.1.1.) in red blood cells}

To determine the activity of SOD in red blood cells, the spectrophotometric assay BIOXYTECH SOD-525 (Oxis International Inc., USA) was used. In this test the property of SOD increasing the autoxidation rate of 5,6,6a,11b-tetrahydro-3,9,10-trihydrobenzofluorene in basic medium to form a chromophore was used. The absorbance of the chromophore was measured at a wavelength of $525 \mathrm{~nm}$. The rate of reaction for the blind and test samples was calculated on the basis of a standard curve, taking into account the absorbance change per unit of time. Determination of SOD activity using the ratio $V_{s} / V_{c}$ is possible due to the supplied test table or on the basis of the calculations according to the manufacturer's formula. The results were expressed as U/g Hgb.

\section{Determination of glutathione peroxidase (EC 1.11.1.9) in red blood cells}

Glutathione peroxidase (GSH-Px) activity in red blood cells was measured by the Ransel test (Randox Laboratories Ltd., UK). This test uses the method of determination of GSH-Px developed by Paglia and Valentine. The change in the absorbance of each sample was determined in 1-minute intervals for $4 \mathrm{~min}$ at a wavelength of $340 \mathrm{~nm}$ at $37^{\circ} \mathrm{C}$ using a spectrophotometer. For the calculations, the high- 
est increase in absorbance subtracted with the result obtained for the blank was used. The enzyme activity was presented in U/g Hgb.

\section{Statistical analysis}

All results were checked for compliance with the Gaussian distribution by the Shapiro-Wilk test, and compliance with the normal distribution was confirmed. For each experimental group, comparisons between groups were performed "before", "immediately after", and "after $10 \mathrm{~h}$ ", using the ANOVA test for repeated measures with comparisons between groups (pairwise comparison). Comparisons between different experimental groups in selected time periods were made using Student's $t$ test with the level of significance at $p<0.05$.

\section{Results}

\section{Level of malondialdehyde}

The level of MDA (Table II) in group 1 before surgery was $3.396 \pm 0.146 \mu \mathrm{mol} / \mathrm{l}$, and increased significantly to $4.383 \pm 0.143 \mu \mathrm{mol} / \mathrm{l}$ immediately after and to $4.203 \pm 0.137 \mu \mathrm{mol} / \mathrm{l}$ at $10 \mathrm{~h}$ after the surgery. The level of MDA before laparoscopy in group 2 was $3.406 \pm 0.136 \mu \mathrm{mol} / \mathrm{l}$ and increased significantly after the operation and $10 \mathrm{~h}$ after laparoscopy to $6.366 \pm 0.147 \mu \mathrm{mol} / \mathrm{l}$, and $5.970 \pm 0.121 \mu \mathrm{mol} / \mathrm{l}$, respectively. A statistically significant difference be- tween groups 1 and 2 in both samples taken after the surgery was also demonstrated.

\section{Level of lipid peroxides}

Levels of lipid peroxides showed a similar direction of change (Table III). In group 1 the value of $8.106 \pm 0.122 \mu \mathrm{mol} / \mathrm{l}$ increased to $10.037 \pm 0.167$ $\mu \mathrm{mol} / \mathrm{l}$ immediately after the operation and to 9.304 $\pm 0.131 \mu \mathrm{mol} / \mathrm{l}$ at $10 \mathrm{~h}$ after surgery. Also, there was a significant difference between the last two results. The level of lipid peroxides in group 2 before laparoscopy was $8.103 \pm 0.136 \mu \mathrm{mol} / /$ and significantly increased immediately after, and at $10 \mathrm{~h}$ after surgery to $12.796 \pm 0.174 \mu \mathrm{mol} / \mathrm{l}$, and to $10.810 \pm 0.211$ $\mu \mathrm{mol} / \mathrm{l}$, respectively. The latter two results and postoperative values between groups 1 and 2 also differed significantly.

\section{Activity of superoxide dismutase}

The activity of SOD in red blood cells of patients in group 1 before the surgery was $2543.1 \pm 91.7 \mathrm{U} /$ $\mathrm{g} \mathrm{Hb}$ (Table IV). The activity decreased to 2027.1 $\pm 67.9 \mathrm{U} / \mathrm{g} \mathrm{Hb}$ immediately after surgery and remained at $2122.3 \pm 91.3 \mathrm{U} / \mathrm{g} \mathrm{Hb}$ at $10 \mathrm{~h}$ after surgery; these changes were significant. The SOD activity in red blood cells of patients in group 2 before the operation was $2516.2 \pm 66.7 \mathrm{U} / \mathrm{g} \mathrm{Hb}$, and decreased to $1567.4 \pm 101.7 \mathrm{U} / \mathrm{g} \mathrm{Hb}$ immediately after surgery and to $1917.2 \pm 82.1 \mathrm{U} / \mathrm{g} \mathrm{Hb}$ at $10 \mathrm{~h}$ after surgery,

Table II. Level of MDA in the plasma of patients undergoing gynecological laparoscopy

\begin{tabular}{|lcc|}
\hline Group & Group $1(<20 \mathrm{~min})[\mu \mathrm{mol} / \mathrm{l}]$ & Group $2(>40 \mathrm{~min})[\mu \mathrm{mol} / \mathrm{l}]$ \\
\hline Before operation & $3.396 \pm 0.146$ & $3.406 \pm 0.136$ \\
\hline Immediately after operation & $4.383^{*} \pm 0.143$ & $6.366^{*, * \star *} \pm 0.147$ \\
\hline Ten hours after operation & $4.203^{*, * *} \pm 0.137$ & $5.970^{*, * *, * * *} \pm 0.121$ \\
\hline
\end{tabular}

Results are presented as mean $\pm S D$. Group $1-n=33$, group $2-n=31$. *Statistically significant differences compared with the values before surgery at $p<0.001 .{ }^{* *}$ Statistically significant differences compared with the values after the operation at $p<0.001 .{ }^{* * *}$ Statistically significant differences compared to the values in group 1 at $p<0.001$. Selected oxidative stress markers in the gynecological laparoscopy.

Table III. Level of lipid peroxides in the plasma of patients undergoing gynecological laparoscopy

\begin{tabular}{|lcc|}
\hline Group & Group $1(<20 \mathrm{~min})[\mu \mathrm{mol} / \mathrm{l}]$ & Group $2(>40 \mathrm{~min})[\mu \mathrm{mol} / \mathrm{l}]$ \\
\hline Before operation & $8.106 \pm 0.122$ & $8.103 \pm 0.136$ \\
\hline Immediately after operation & $10.037^{*} \pm 0.167$ & $12.796^{* * * * *} \pm 0.174$ \\
\hline Ten hours after operation & $9.304^{* * * *} \pm 0.131$ & $10.810^{* * * * * * *} \pm 0.211$ \\
\hline
\end{tabular}

Results are presented as mean $\pm S D$. Group $1-n=33$, group $2-n=31$. *Statistically significant differences compared with the values before surgery at $p<0.001$. ${ }^{*}$ Statistically significant differences compared with the values after the operation at $p<0.001 .{ }^{* * *}$ Statistically significant differences compared to the values in group 1 at $p<0.001$ 
Table IV. Activity of SOD in red blood cells of patients undergoing gynecological laparoscopy

\begin{tabular}{|lcc|}
\hline Group & Group $1(<20 \mathrm{~min})[\mathrm{U} / \mathrm{g} \mathrm{Hb}]$ & Group $2(>40 \mathrm{~min})[\mathrm{U} / \mathrm{g} \mathrm{Hb}]$ \\
\hline Before operation & $2543.1 \pm 91.7$ & $2516.2 \pm 66.7$ \\
\hline Immediately after operation & $2027.1^{*} \pm 67.9$ & $1567.4^{*, * * *} \pm 101.7$ \\
\hline Ten hours after operation & $2122.3^{*} \pm 91.3$ & $1917.2^{*, * *, * * *} \pm 82.1$ \\
\hline
\end{tabular}

Results are presented as mean $\pm S D$. Group $1-n=33$, group $2-n=31$. *Statistically significant differences compared with the values before surgery at $p<0.001$. ${ }^{* *}$ Statistically significant differences compared with the values after the operation at $p<0.001 .{ }^{* * *}$ Statistically significant differences compared to the values in group 1 at $p<0.001$.

Table V. Activity of glutathione peroxidase in red blood cells of patients undergoing gynecological laparoscopy

\begin{tabular}{|lcc|}
\hline Group & Group $1(<20 \mathrm{~min})[\mathrm{U} / \mathrm{g} \mathrm{Hb}]$ & Group $2(>40 \mathrm{~min})[\mathrm{U} / \mathrm{g} \mathrm{Hb}]$ \\
\hline Before operation & $35.07 \pm 1.22$ & $34.11 \pm 1.83$ \\
\hline Immediately after operation & $28.67^{\star} \pm 1.88$ & $22.17^{*, * * *} \pm 2.26$ \\
\hline Ten hours after operation & $29.20^{*} \pm 1.39$ & $25.89^{* * * *} \pm 1.87$ \\
\hline
\end{tabular}

Results are presented as mean $\pm S D$. Group $1-n=33$, group $2-n=31$. ${ }^{*}$ Statistically significant differences compared with the values before surgery at $p<0.001$. ${ }^{* *}$ Statistically significant differences compared with the values after the operation at $p<0.001 .{ }^{* * *}$ Statistically significant differences compared to the values in group 1 at $p<0.001$.

with statistical significance. The results obtained after the surgery in groups 1 and 2 also differed significantly.

\section{Activity of glutathione peroxidase}

The GSH-Px activity in red blood cells of patients in group 1 before the surgery was $35.07 \pm 1.22 \mathrm{U} /$ $\mathrm{g} \mathrm{Hb}$ (Table V), decreased statistically significantly to $28.67 \pm 1.88 \mathrm{U} / \mathrm{g} \mathrm{Hb}$ immediately after, and remained at the level of $29.20 \pm 1.39 \mathrm{U} / \mathrm{g} \mathrm{Hb}$ at $10 \mathrm{~h}$ after the operation. In patients from group 2 activity of GSHPx before the operation was $34.11 \pm 1.83 \mathrm{U} / \mathrm{g} \mathrm{Hb}$. Peroxidase activity significantly decreased to a value of $22.17 \pm 2.26 \mathrm{U} / \mathrm{g} \mathrm{Hb}$ immediately after surgery and remained at a level of $25.89 \pm 1.87 \mathrm{U} / \mathrm{g} \mathrm{Hb}$ $10 \mathrm{~h}$ after the surgery. Postoperative values of group 1 and 2 also differed significantly.

\section{Discussion}

Professor Kurt Semm from Kiel started in the 1980s the era of laparoscopic gynecological operations throughout Europe and the United States of America. Also in 1983, as a gynecologist, he made the first laparoscopic appendectomy [10]. For patients it is the preferred method compared to the open surgical approach or natural orifice translumenal endoscopic surgery (NOTES) [11]. The advantage of laparoscopy is less stress than in the open operative techniques [8]. One of the major components of the operative stress is oxidative stress [12]. Laparoscopic technique, being less traumatic, is characterized, according to most authors, by less severe oxidative stress than the open technique used in the same procedure [12-14].

Our research, based on the model of gynecological laparoscopy, concerned groups differing in duration of surgery. In our study we found an increase in the level of lipid peroxides and MDA, in the samples taken 5 min after the release of pneumoperitoneum and $10 \mathrm{~h}$ after the surgery. The activity of antioxidant enzymes SOD and GSH-Px were decreased. This direction of change was observed in both groups of patients. Our results can be compared with a few reports on oxidative stress in patients undergoing surgery for gynecological reasons. These include the work of Taskin et al. [15], who carried out laparoscopic operations of ovarian tumors. They found decreasing activity of antioxidant enzymes (SOD, catalase and GSH-Px) and glutathione levels in homogenates of the peritoneum slices. Zhang et al. [8], in turn, in patients with uterus fibroids, found increased pro-oxidative activity $5 \mathrm{~min}$ after the release of pneumoperitoneum. The activity of GSH-Px and total antioxidant activity in this study showed a slight decrease. Changes in the activity 
of antioxidant systems were also seen $24 \mathrm{~h}$ after the surgery. The probable cause of these changes, according to the author, was the ischemia-reperfusion syndrome. These results correlate with those obtained in our study and indicate the development of oxidative stress in the course of laparoscopy, performed at high pressure pneumoperitoneum.

Aran et al. [9] in patients undergoing gynecological laparoscopy observed an increase in the level of ischemia-modified albumin, treating it as an exponent of oxidative stress. In that study the level of MDA did not increase, which was possibly related to the treatment of the sample taken at 10 min after anesthesia as a control.

Further discussion on pro-oxidant activity can be found in the works concerning laparoscopic surgery by Bukan et al. [12], Glantzounis et al. [16], and Zengin et al. [17]. All the authors cited above obtained, in samples taken after the release of pneumoperitoneum, results in line with ours. Evaluation of pro-oxidant activity at $12 \mathrm{~h}$, a period similar to that in our work, was conducted only by Zengin et al. [17], and the results are compatible with ours.

Reduction of SOD and GSH-Px, as in our study, in the course of laparoscopic cholecystectomy was demonstrated by Olakowski et al. [18]. Stipančić et al. [19], in turn, using the same model in the blood plasma analyzed total antioxidant status (TAS) level and SOD activity on the first, third and seventh postoperative day. They found no changes in the level of TAS, and an increase in SOD activity on the $7^{\text {th }}$ day after surgery, compared to the preoperative period.

Some reports dealing with the development of oxidative stress in the course of laparoscopy are based on experimental studies. Antioxidant behavior of the system in the course of experimental laparoscopy was analyzed by Akbulut et al. [20], who noted a decrease in SOD activity after a laparoscopic donor nephrectomy. Similarly Cevrioglu et al. [21] confirmed the decrease in the activity of glutathione reductase and the level of reduced glutathione in erythrocytes and peritoneum of rats. The cause of reduced activity of antioxidant enzymes in the course of laparoscopy, which is an example of ischemia-reperfusion syndrome, can be, according to Sun et al. [22], the reduction of their synthesis, consumption in the processes of removing free radicals or deactivation by excess of reactive oxygen species. In the course of laparoscopy, one of the factors that can stimulate pro-oxidative mechanisms is the gas fed to produce pneumoperitoneum. Carbon dioxide is most often used for this purpose. However, according to Wong et al. [23] it causes acidosis, which can stimulate the local inflammatory response in the peritoneum [24]. This supposition is confirmed by the study of Redmond et al. [25]. Pross et al. [26] observed increased lipid peroxidation in lung tissue. It was related to increased migration and activation of neutrophils, which reached a maximum at $18 \mathrm{~h}$ after the end of the pneumoperitoneum. Neutrophil activation may be one of the factors responsible for the persistent increased levels of MDA and peroxides in our study at $10 \mathrm{~h}$ after the surgery. In order to eliminate the adverse effects of $\mathrm{CO}_{2}$ in the course of laparoscopy, other gases were tested, especially helium [27, 28]. Shuto et al. [28] obtained similar results using both $\mathrm{CO}_{2}$ and helium, and stated that hemodynamic changes depend on the value of the intraperitoneal pressure, and not on the type of gas used.

Glantzounis et al. [29] observed the development of oxidative stress in patients undergoing laparoscopic cholecystectomy, and drew attention to the role of ischemia-reperfusion syndrome in the generation of free radicals. Experimental studies on animals showed that peritoneal edema increases the intraperitoneal pressure, resulting in ischemia of abdominal organs. This, in turn, increases the formation of free radicals [30]. The occurrence of abdominal ischemia was confirmed in humans during laparoscopic cholecystectomy [31]. A thorough discussion of abdominal organs ischemia under pneumoperitoneum can also be found in the work of Schäfer and Krähenbühl [32]. All cited authors agree as to the occurrence of ischemia in abdominal organs during pneumoperitoneum. Guven et al. [33] in experimental studies observed a reduction in flow within the ovary with subsequent development of oxidative stress.

Ischemia caused by pneumoperitoneum is transient. After the release of pneumoperitoneum normal tissue perfusion is restored [34]. Therefore, laparoscopy should be considered as an example of ischemia-reperfusion syndrome.

Zweier et al. and Ambrosio et al. [35, 36] noted an increase of free radical generation in 10-20 s of reperfusion. Other authors have demonstrated peak generation of free radicals in the $5^{\text {th }}$ [37] and in the $15^{\text {th }}$ min of reperfusion [38]. In the early period of reperfusion, even in the reduced oxygen availability, 
in vascular endothelial cells increased $\mathrm{O}_{2}$ conversion to a reactive form is observed, with a severity proportional to the depth of hypoxia [39].

Glantzounis et al. [40], summarizing the reports on changes in the liver in the course of ischemiareperfusion syndrome, stated that activation of neutrophils releases ROS [41]. However, the main source of ROS in ischemic tissues during reperfusion is a xanthine oxidase (XO) system [42]. There is a consensus that during laparoscopy ischemia-reperfusion syndrome is growing at an average level, and there is an increase in XO activity in the gut [43] There are cases of intestinal necrosis during prolonged laparoscopic procedures, which Hasson et al. [44] associate with critical ischemia, rarely observed in patients with good general condition.

In our study, one of the objectives was to determine whether the duration of laparoscopy may correlate with the severity of oxidative stress. The obtained results indicate that the short-term procedure is combined with a benign course of oxidative stress. Peroxide and MDA levels were statistically higher in patients whose operation time exceeded 40 min, compared with the short-term laparoscopy. Dismutase activity in samples taken immediately after the operation was lower in patients operated on for over $40 \mathrm{~min}$. A statistically significant decrease in GSH-Px activity was also noted in this group of patients. In the available literature there are no studies using a similar model and analyzing these markers.

The available literature lacks reports indicating the scope of laparoscopy performed and the type of operating procedures, mainly indicating the duration of the ischemia-reperfusion syndrome and more broadly the effect of duration of pneumoperitoneum on the activity of pro- and antioxidant mechanisms.

Quite useful for the interpretation of the development of oxidative stress in our study may be a correlation between the duration of laparoscopy and the severity of ischemia-reperfusion syndrome, the main source of free radicals. Unsal et al. [45], during experimental laparoscopy, found a dependence of severity of any ischemia-reperfusion syndrome on both the intraperitoneal pressure and the duration of pneumoperitoneum. Similarly, Schilling et al. [46], at a constant intraperitoneal pressure, observed progressive reduction of the flow in the visceral area. Skorzyński et al. [47] published the results of hemodynamic parameters such as the speed of blood flow in the descending aorta, total peripheral vascular resistance, and stroke volume in patients undergoing gynecological laparoscopy. The procedures were divided into three groups: lasting up to $30 \mathrm{~min}$, from 30 to $60 \mathrm{~min}$, and over $60 \mathrm{~min}$. Statistically significant differences were found in the results obtained during the medium- and long-term laparoscopy compared to short-term laparoscopy. This confirms the importance of pneumoperitoneum duration for the formation of hemodynamic disorders. Emir et al. [48] noted an increase of xanthine oxidase activity in the large intestine of animals undergoing laparoscopy, 20 min after pneumoperitoneum was established. Zweier et al. [35] believe that there is a correlation between the severity of oxidative stress and the duration of ischemia, which can lead to inactivation of antioxidant enzymes. This was also corroborated by Porreca et al. [49], who reported an increase in the activity of catalase and GSH-Px in an ischemia-reperfusion model of myocardial infarction, in which rats were subjected to $10 \mathrm{~min}$ of ischemia followed by 30 min of reperfusion. Extending the ischemic time in this model led to reduced activity of the enzymes.

In the available literature, two opinions concerning the relationship between the deepening of oxidative stress and the duration of laparoscopy are presented. Polat et al. [50] stated that the amount of free radicals produced during pneumoperitoneum depends not only on the severity of ischemia-reperfusion injury, but also on its duration. A different point of view is presented by Urena et al. [51], who analyzed the level of isoprostanes in the urine of patients undergoing urological laparoscopy. Urological operations are performed, however, without pneumoperitoneum, and the formation of isoprostanes depends on sources other than the formation of MDA and peroxides. Our results indicate that shorter duration of the laparoscopy is associated with less severe oxidative stress. However, further studies are necessary to analyze the role of pneumoperitoneum duration and the types of laparoscopic procedures for the development of oxidative stress.

\section{Conclusions}

In the course of gynecological laparoscopy the development of oxidative stress is manifested by increased levels of lipid peroxides and MDA and reduced activity of the antioxidant enzymes SOD and glutathione peroxidase. Degree of oxidative stress correlates with the duration and extent of laparoscopic surgery. 


\section{Conflict of interest}

\section{The authors declare no conflict of interest.}

\section{References}

1. Burpee SE, Kurian M, Murakame Y, et al. The metabolic and immune response to laparoscopic versus open liver resection. Surg Endosc 2002; 16: 899-904.

2. Wilmore DW. Alterations in protein, carbohydrate, and fat metabolism in injured and septic patients. J Am Coll Nutr 1983; 2: 3-13.

3. Mudron P, Herzog K, Höltershinken M, Rehage J. Effects of abdominal surgery on thiobarbituric acid reactive substances and plasma anti-oxidative capacity in dairy cows. J Vet Med A Physiol Pathol Clin Med 2007; 54: 441-4.

4. Szymczyk G, Bełtowski J, Marciniak A. Kotarski J. Assessment of serum lipid peroxide levels and antioxidant status in females who had undergone total abdominal hysterectomy without closing of the peritoneum [Polish]. Ginekol Pol 2003; 74: 1397-403.

5. Abe Y, Miyake M, Horiuchi A, et al. Changes in the productivity of cytokines and active-oxygen in peripheral blood cells following surgery. Surg Today 1992; 22: 15-8.

6. Deitch EA. Bridges W, Baker J, et al. Hemorrhagic shock-induced bacterial translocation is reduced by xanthine oxidase inhibition or inactivation. Surgery 1988; 104: 191-8.

7. Anup R, Aparna V, Pulimood A, Balasubramanian KA. Surgical stress and the small intestine: role of oxygen free radicals. Surgery 1999; 125: 560-9.

8. Zhang GL, Liu GB, Huang QL, Xing FQ. Comparative study of the impacts of laparoscopic and open laparatomic surgeries on oxidative stress in patients with uterine myoma [Chinease]. Di Yi Jun Yi Da Xue Xue Bao 2004; 24: 907-9

9. Aran T, Unsal MA, Guven S, et al. Carbon dioxide pneumoperitoneum induces systemic oxidative stress: a clinical study. Eur J Obstet Gynecol Reprod Biol 2012; 161: 80-3.

10. Bartnicki J, Gąsior S. Laparoscopy in gynaecology - chracteristics of the current state in Germany [Polish]. Videosurgery Miniinv 2008; 3: 134-8.

11. Kobiela J, Stefaniak T, Laski D, et al. NOTES. Study on patients' perspective. Videosurgery Miniinv 2013; 8: 232-7.

12. Bukan MH, Bukan N, Kaymakcioglu N, Tufan T. Effects of open vs. laparoscopic cholecystectomy on oxidative stress. Tohoku J Exp Med 2004; 202: 51-6.

13. Gal I, Roth E, Lantos J, et al. Surgical trauma induced by laparoscopic cholecystectomy [Hungarian]. Orv Hetil 1998; 139: 739-46.

14. Grabowski A, Korlacki W, Pasierbek M. Laparoscopy in elective and emergency management of ovarian pathology in children and adolescents. Videosurgery Miniinv 2014; 9: 164-9.

15. Taskin O, Buhur A, Birincioglu M, et al. The effects of duration of $\mathrm{CO} 2$ insufflation and irrigation on peritoneal microcirculation assessed by free radical scavengers and total glutathione levels during operative laparoscopy. J Am Assoc Gynecol Laparosc 1998; 5: 129-33.
16. Glantzounis GK, Tsimaris I, Tselepis AD, et al. Alterations in plasma oxidative stress markers after laparoscopic operations of the upper and lower abdomen. Angiology 2005; 56: 459-65.

17. Zengin K, Taskin M, Sakoglu N, et al. Systemic inflammatory response after laparoscopic and open application of adjustable banding for morbidly obese patients. Obes Surg 2002; 12: 276-9.

18. Olakowski M, Lampe P, Mekle H, Stefański L. Changes in activity of antioxidant enzymes in the early period after classical and laparoscopic cholecystectomy [Polish]. Wiad Lek 1997; 50 (S1P1): 213-7.

19. Stipančic I, Zarkovic N, Servis D, et al. Oxidative stress markers after laparoscopic and open cholecystectomy. J Laparoendosc Adv Surg Tech A 2005; 15: 347-52.

20. Akbulut G, Serteser M, Polat C, et al. Changes in tissue-oxidative stress markers in an experimental model of laparoscopic donor nephrectomy. Transplantation 2002; 74: 1768-72.

21. Cevrioglu AS, Yilmaz S, Koken T, et al. Comparison of the effects of low intra-abdominal pressure and ischaemic preconditioning on the generation of oxidative stress markers and inflammatory cytokines during laparoscopy in rats. Hum Reprod 2004; 19: 2144-51.

22. Sun JS, Lu FJ, Huang WC, et al. Antioxidant status following acute ischemic limb injury: a rabbit model. Free Radic Res 1999; 31: 9-21.

23. Wong YT, Shah PC, Birkett DH, Brams DM. Carbon dioxide pneumoperitoneum causes severe peritoneal acidosis, unaltered by heating, humidification, or bicarbonate in a porcine model. Surg Endosc 2004; 18: 1498-503.

24. West MA, Hackam DJ, Baker J, et al. Mechanism of decreased in vitro murine macrophage cytokine release after exposure to carbon dioxide: relevance to laparoscopic surgery. Ann Surg 1997; 226: 179-90

25. Redmond HP, Watson RW, Houghton T, et al. Immune function in patients undergoing open vs. laparoscopic cholecystectomy. Arch Surg 1994; 129: 1240-6.

26. Pross M, Schulz HU, Flechsig A, et al. Oxidative stress in lung tissue induced by $\mathrm{CO} 2$ pneumoperitoneum in the rat. Surg Endosc 2000; 14: 1180-4.

27. Yilmaz S, Polat C, Kahraman A, et al. The comparison of the oxidative stress effects of different gases and intra-abdominal pressure in an experimental rat model. J Laparoendosc Adv Surg Tech A 2004; 14: 165-8.

28. Shuto K, Kitano S, Yoshida T, et al. Hemodynamic and arterial blood gas changes during carbon dioxide and helium pneumoperitoneum in pigs. Surg Endosc 1995; 9: 1173-8.

29. Glantzounis GK, Tselepis AD, Tambaki AP, et al. Laparoscopic surgery-induced changes in oxidative stress markers in human plasma. Surg Endosc 2001; 15: 1315-9.

30. Sammour T, Mittal A, Loveday BP, et al. Systemic review of oxidative stress associated with pneumoperitoneum. Br J Surg 2009; 96: 836-50

31. Eleftheriadis E, Kotzampassi K, Botsios D, et al. Splanchnic ischemia during laparoscopic cholecystectomy. Surg Endosc 1996; 10: 324-6

32. Schäfer M, Krähenbühl L. Effect of laparoscopy on intra-abdominal blood flow. Surgery 2001; 129: 385-9. 
33. Guven S, Muci E, Unsal MA, et al. The effects of carbon dioxide pneumoperitoneum on ovarian blood flow, oxidative stress markers, and morphology during laparoscopy: a rabbit model. Fertil Steril 2010; 93: 1327-32.

34. Samel ST, Neufang T, Mueller A, et al. A new abdominal cavity chamber to study impact of increased intra-abdominal pressure on microcirculation of gut mucosa by using video micros copy in rats. Crit Care Med 2002; 30: 1854-8.

35. Zweier JL, Flaherty JT, Weisfeldt ML. Direct measurement of free radical generation following reperfusion of ischemic myocardium. Proc Natl Acad Sci USA 1987; 84: 1404-7.

36. Ambrosio G, Zweier JL, Flaherty JT. The relationship between oxygen radical generation and impairment of myocardial energy metabolism following post-ischemic reperfusion. J Mol Cell Cardiol 1991; 23: 1359-74.

37. Nohl H, Jordan W. The mitochondrial site of superoxide formation. Biochem Biophys Res Commun 1986; 138: 533-9.

38. Khalid MA, Ashraf M. Direct detection of endogenous hydroxyl radical production in cultured adult cardiomyocytes during anoxia and reoxygenation. Is the hydroxyl radical really the most damaging radical species? Circ Res 1993; 72: 725-36.

39. Bertuglia S, Giusti A. Microvascular oxygenation and oxidative stress during postischemic reperfusion. Adv Exp Med Biol 2005; 566: 23-9.

40. Glantzounis GK, Salacinski HJ, Yang W, et al. The contemporary role of antioxidant therapy in attenuating liver ischemia-reperfusion injury: a rewiev. Liver Transpl 2005; 11: 1031-47.

41. Jaeschke H. Reactive oxygen and mechanisms of inflammatory liver injury. J Gastroenterol Hepatol 2000; 15: 718-24.

42. Granell S, Bulbena O, Genesca M, et al. Mobilization of xanthine oxidase from gastrointestinal tract in acute pancreatitis. BMC Gastroenterol 2004; 4: 1.

43. Yilmaz S, Koken T, Tokyol C, et al. Can preconditioning reduce laparoscopy-induced tissue injury? Surg Endosc 2003; 17: 819-24.

44. Hasson HM, Galanopoulos C, Langerman A. Ischemic necrosis of small bowel following laparoscopic surgery. JSLS 2004; 8: 159-63.

45. Unsal MA, Imamoglu M, Kadioglu M, et al. The acute alterations in biochemistry, morphology, and contractility of rat-isolated terminal ileum via increased intra-abdominal pressure. Pharmacol Res 2006; 53: 135-41.

46. Schilling MK, Redaelli C, Krähenbühl L, et al. Splanchnic microcirculatory changes during CO2 laparoscopy. J Am Coll Surg 1997; 184: 378-82.

47. Skorzyński W, Jakiel G, Przesmycki K. Haemodynamics during gynaecological laparoscopy [Polish]. Anestezjol Intens Ter 2008; 40: 7-12.

48. Emir $\mathrm{H}$, Akman $\mathrm{M}$, Belce $\mathrm{A}$, et al. Is intestinal ischaemia a risk of laparoscopy? An experimental study in rabbits. Eur J Pediatr Surg 2001; 11: 158-62.

49. Porreca E, Del Boccio G, Lapenna D, et al. Myocardial antioxidant defense mechanisms: time related changes after reperfusion of the ischemic rat heart. Free Radic Res 1994; 20: 171-9.

50. Polat C, Yilmaz S, Serteser M, et al. The effect of different intraabdominal pressures on lipid peroxidation and protein oxidation status during laparoscopic cholecystectomy. Surg Endosc 2003; 17: 1719-22.
51. Urena R, Mendez F, Ruiz-Deya G, et al. Does prolonged pneumoperitoneum affect oxidative stress compared with open surgical procedures? J Endourol 2005; 19: 221-4.

Received: 2.10.2014, accepted: 26.10.2014. 